East African Medical Journal Vol. 87 No. 1 January 2010

CANCRUM ORIS IN AN ADULT WITH HUMAN IMMUNODEFICIENCY VIRUS INFECTION: CASE REPORT

K.J. Koech, BDS, MDS (OMFS), Consultant Oral and Maxillofacial Surgeon, Kenyatta National Hospital, P.O. Box 1955200202, Nairobi, Kenya

\title{
CANCRUM ORIS IN AN ADULT WITH HUMAN IMMUNODEFICIENCY VIRUS INFECTION: CASE REPORT
}

\author{
K.J. KOECH
}

\section{SUMMARY}

\begin{abstract}
New cases of cancrum oris in adults are rare and there are no previous reports in the literature from Kenya. Since noma is related to factors associated with poverty and immunosuppression, reducing the incidence of noma can be achieved with improvement in socio-economic status of communities and prevention of HIV infection. An unusual case of a human immunodeficiency virus (HIV) infected a 49 year old female with a full thickness cheek defect following a recent cancrum oris infection is reported. The disfiguring defect was successfully reconstructed using a two staged delto-pectoral flap with a satisfactory aesthetic and functional outcome.
\end{abstract}

\section{INTRODUCTION}

Noma which means "to devour" or "something quickly spreading" in the Greek language is a primary oral infection that spreads locally and invariably result in various degrees of peri-oral soft and hard tissue destruction $(1,2)$. The condition has been described with various names which include gangrenous stomatitis, cancrum oris, among others found in the literature (2-4). The primary infection in noma is believed to be gingival. However, there appears to be an overwhelmingly high bacterial load of normal oral micro-organisms, breaking the resistance of a failing immunity $(2,4)$. It has for a long time been known that there is an association between noma and factors such as poverty, poor oral hygiene, malnutrition, malaria, preceding viral infections especially measles and immunosuppressive conditions including HIV infection (1-4,7). The pathophysiology of the disease is still as yet unclear, being a subject of several theories which include vascular, bacterial and viral (1).

According to the World Health Organisation (WHO) noma has an annual global incidence of 14000 cases (5). Most of these cases are found in the poor regions of sub-Saharan Africa in the socalled noma belt, suggesting that noma is a tropical disease. However, declining cases from the more developed parts of the world suggests that it is more related to poverty $(2,7)$. Noma has a high mortality rate of $90 \%$ in untreated cases and the survivors of the disease suffer from the stigma of debilitating disfigurement and functional defects such as trismus, oral incontinence and speech problems 1-5 These cases are estimated to be numbering about 770,000 all over the world and would require very challenging and prolonged reconstructive options $(1-4,6,10)$. Although noma is predominantly a childhood disease adult cases especially in association with secondary immunodeficiency including that from HIV infection have been reported $(3,5,9)$. Literature on noma from Kenya has been scanty. Whether this is a reflection of the rarity of the disease is difficult to fathom, an unusual case of a HIV infected adult female who presented with an oro-cutaneous fistular on the cheek resulting from a recent noma infection is reported.

\section{CASE REPORT}

A 49 year old female nursery school teacher, married with three grown children, from the Northern semiarid part of Kenya was admitted to the maxillofacial surgery ward of Kenyatta National Hospital (KNH) in May 2008 with an open wound on the left cheek. She was referred from her district hospital where she had been admitted over the previous four days with the wound which had burst open following one week of pain and swelling of the cheek. Her past dental and medical history was significant only for generalised "boils" which had healed without treatment. She was in a fair general condition with noevidence of systemic disease and had a full thickness defect of the left cheek measuring $5 \mathrm{~cm}$ whichexposed the mandibular cortex, together with molar and premolar roots (Figure 1). The margins of the defect were in advanced stages of wound healing and the exposed mandible, although partially covered by granulation tissue, showed areas of suppuration. A diagnosis of cancrum oris (noma) in its resolution stage was made and the patient was put on intra-venous Augmentin ${ }^{\mathrm{R}}$ and Flagyl ${ }^{\mathrm{R}}$. A full haemogram and urea and electrolyte investigation 
were within normal limits except for anaemia of $10.9 \mathrm{~g} / \mathrm{dl}$ which did not warrant a blood transfusion. She was taken to theatre two weeks later where under general anaesthesia excision of the wound margin was done and after debridement and extraction of the compromised teeth reconstruction was initiated using a medially based pedicled delto-pectoral flap which was folded to enable creation of an oral lining. She made an uneventful recovery with complete survival of the flap and had her reconstruction completed three weeks later with the rest of the flap being returned to the donor site, leaving the deltoid area covered by a skin graft, She made a complete recovery with good healing of the margins and a good colour match (Figure 2). Following antiretroviral drug adherence counselling she was discharged to her district hospital from where she would be managed for HIV infection.

Figure 1

Pre-operative picture showing a full thickness defect with healed wound margins

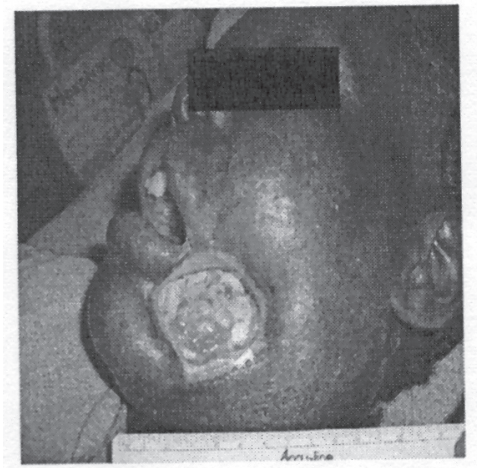

Figure 2

Post-operative picture (2 weeks) showing healed flap and good colour match

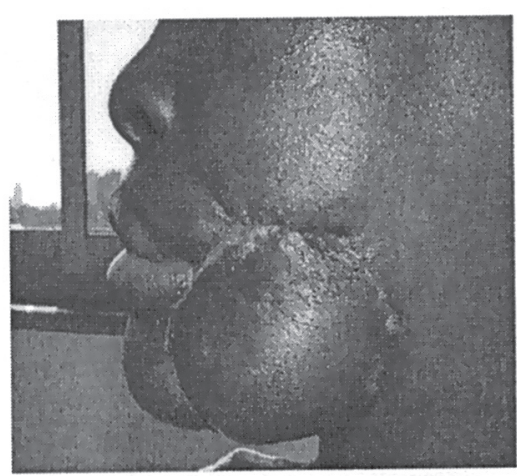

DISCUSSION

Cases of recently healed and active noma among adults are rare making the current case unusual. Interestingly, despite the association between noma and immunosuppressive conditions including HIV /
AIDS there are hardly any studies which demonstrate a commensurate increase in the incidence of the disease since the advent of the HIV epidemic in the tropics. This could imply therefore, that although HIV infection was a predisposing factor in the current case environmental factors antecedent in poverty may have contributed to her illness. Fusobacterium necrophorum, a normal commensal in the gut of herbivores has been identified from several studies as an important pathogenic micro-organism in noma and it is thought to find its way into the human oral cavity via animal faecal contamination. It is thought that in the presence of a damaged mucosa, and in association with Prevotela intermedia noma is initiated and established in humans (8-10). Our patient originated from a pastoralist community which has a close association with cattle and might have been exposed to fusobacterium necrophorum. This factor, among others, together with the fact her pastoralist community is exposed to famine may have contributed to noma in our patient. Classically noma has been associated with severe malnutrition and preceding viral febrile illnesses in children but apart from the history of "boils" which healed spontaneously the patient had been, by her own account, healthy before the currentillness. This therefore implies that noma is not predictable, Although the pathogenesis of noma is still poorly understood studies in Nigeria have shown that serum concentrations of pro-inflammatory cytokines (IL-6, 1L-18, IL-12, INF) and soluble inhibitors (TNFRp55,TNFR-p75 and 1L-1ra), and antiinflammatory cytokines are higher among children with acute noma than in healthy urban children of similar age, but there is less difference between affected children and their malnourished village counterparts without noma (11). However, the presence of other infections which cause an increased production of cytokines could not be ruled out in the malnourished village children. Nonetheless, it can be concluded that noma is an immunopathological response to potent bacterial factors resulting in uncontrolled production of inflammatory mediators.

Early surgical intervention after active disease as was done in this case is known to reduce the sequelae of fibrosis and trismus and gives better functional results (6-8). The choice of reconstructive technique depends on the site, size, the surgeon's preference and available expertise. The delto-pectoral flap was chosen for this case because of its reliability and the fact that the site of the defect allowed for a good reach of the flap. The flap was folded to create an oral lining which is an important goal in noma reconstruction for full thickness defects. It is also achieved using different techniques which have been described elsewhere (6). Folded supraclavicular flap has been described as a simple and useful flap in noma reconstruction but reports of distal flap necrosis have been highlighted as 
a major limitation $(6,10)$. Moreover, cases of complete flap necrosis have been reported when this flap has been designed as an island and tunnelled through the neck (10). It is therefore, important that the surgeon is familiar with the different techniques to be able to sufficiently treat noma defects.

\section{ACKNOWLEDGEMENTS}

To Dr. E. Sanya, Dr. B. Nyamu and the interns in oral and maxillofacial surgery for helping with the management of this patient and to the administration of $\mathrm{KNH}$ for permission to publish this report.

\section{REFERENCES}

1. Marck, K.W.Ahistory of Noma, "the face of poverty". Plast. Recons. Surg. 2003; 111: 1702-1707.

2. Baratti-mayer, D., Pittet, B., Montandon, D. et al. Noma:An "infectious" disease of unknown aetiology. Lancet. infect. Dis. 2003; 3: 419.

3. Chidzonga, M.M. and Mahomva, L. Noma (Cancrum Oris) in human immunodeficiency virus infection and acquired immunodeficiency syndrome (HI V and AIDS): Clinical experience in Zimbabwe. J. Oral. Maxillofac. Surg. 2008; 66: 475-485.

4. Kaimenyi, J.T. and Guthua, S.W. Residual facial deformity resulting from cancrum oris: Acase report. East Afr. Med. J. 1994; 71: 476-478.
5. Bourgeois, D.M. and Leclercq, M.H. The World Health Organization initiative in noma. Oral Dis. 1999; 5: 171-174.

6. Heitland, A.S. and Pallua, N. The single and double folded sypraclavicular island flap as a new therapy option in the treatment of large facial defects in noma patients. Plast. Reconstr. Surg. 2005; 115: 1591-1596.

7. Enwonwu, C.O., Falkler, W.A., Idigbe, E.O. and Savage, K.O. Noma (cancrum oris): questions and answers. Oral Dis. 1999; 5: 144-149.

8. Falkler, W. A., Enwonu, C.O. and Idigbe, E.O. Microbiogical understanding and mysteries of Noma, (cancrum oris). Oral Dis. 1999; 5: 150-155.

9. Majmundar, K.V. and Heller, A.J. A rare case report about noma or cancrum oris in a neutropenic patient. Otolaryngology-Head and Neck Surg. 2004; 131: 112.

10. Hartman, E.H.M., Van Damme, P.A. and Souminen, S.H.H. The use of pedicled supraclavicular flap in noma reconstructive surgery. Plast. Recons. Surg. 2006; 181: 270-271.

11. Phillips, R.S., Enwonwu, C.O. and Falkler, W. A. Proversus anti-inflammatory cytokine profile in African children with acute oro-facial noma (cancrum oris, noma). Eur. Cytokine Netw. 2005; 16: 70-77. 